\title{
Immunotropic effect of oyster mushroom beta- glucans, in combination with birch tree triterpene betulin, and beastim, dipeptide of gamma-D-glutamyl-tryptophan
}

\author{
Valentina Konusova ${ }^{1}$, Mohamed Frioui ${ }^{2}$, Mark Shamtsyan ${ }^{2, *}$, Eugene Vorobeychikov ${ }^{2}$, and \\ Andrey Simbirtsev ${ }^{1}$ \\ ${ }^{1}$ State Institute of Highly Pure Biopreparations, 7, Pudozhsakya str., 197110, St. Petersburg Russia \\ ${ }^{2}$ State Institute of Technology (Technical University), 190013, Moskovsky prospect, 26, St. \\ Petersburg, Russia
}

\begin{abstract}
Immunotropic effect of oyster mushroom beta-glucans, birch tree triterpenes and dipeptide of gamma-D-glutamyl-tryptophan were studied on white male mice. The study demonstrated that bestim, betaglucan, as well as a combined preparation consisting of bestim, betulin and beta-glucan administered in a single dose) have an immunotropic effect, which is confirmed by reliable increase in the mass of the thymus, as well as the "mass ratio of the thymus". The reaction of the spleen of animals to the studied preparations was less obvious. Stimulation of humoral immunity of animals by these preparations was also detected.
\end{abstract}

\section{Introduction}

Mediated through the adaptive mechanisms effect on the immune system of various compounds originated from plants, fungi and bacteria is currently insufficiently studied, although interesting and promising. Their influence on the body as a whole, and on the immunity in particular, is more local and is not accompanied by undesirable effects from the nervous and endocrine systems. In recent years, there has been a significant increase in interest in the possibility of creating high-quality phytopreparations while maintaining a standard, predictable and "dosed" effect on immunity while maintaining high safety of phytopreparations. Many phytotherapists recommend natural products made from medicinal plants and mushrooms for "soft" therapy, for the treatment of numerous diseases and general strengthening of immunity.

Currently, there is much growing interest in the use of these medicinal plants as modulators of the complex immune system. Through a number of vast researches conducted in the area, it is being explored that many of the chemicals in the form of alkaloids, flavonoids, terpenoids, polysaccharides, lactones, and glycoside products are responsible to cause alterations in the immunomodulatory properties [1].

* Corresponding author: mark.shamtsyan@yandex.ru 
Recently, corona viral epidemic raised the issue of developing effective antiviral agents at the earliest to prevent further losses. Natural products have always played a crucial role in drug development process against various diseases, which resulted in screening of such agents to combat emergent mutants of corona virus. [2]

The purpose of this experiment was to study the effect of betulin, beastim, fungal betaglucan, and also a combination of these substances on some indicators of the immune system of mice.

Edible fungi are known to have been used thousands of years ago in ancient civilizations for their healing powers as well as to increase human longevity [2]. Glucans $b$ $(1 \rightarrow 3), \mathrm{b}(1 \rightarrow 4)$, and $\mathrm{b}(1 \rightarrow 6)$ are a key reason fungi are used as food additives and in pharmacology; they have also shown beneficial effects when used in the treatment of various diseases [3 -5].

Beta-glucans are components of mushroom cell walls. A high level of biological efficiency has been found in beta-glucans, especially beta-1,3-D-glucans and beta-1,6-Dglucans isolated from some basidiomycetes.

Betulin is a pentacyclic triterpene present in the bark of the birch tree and other vegetal sources. Birch tree has been known for a long time for its healing properties; birch bark oil was used in folk medicine for the treatment of skin diseases (eczema, psoriasis). Outer bark of birch (Betula alba cortex) contains pentacyclic triterpenes, mainly betulin (BE, up to $34 \%$ ) [6]. Birch can be a large and feasible source of raw material for betulin extraction [7].

Birch bark has been used in folk medicine for many centuries, but today, with the help of modern technology, it has been possible to obtain an extract with $80-90 \%$ betulin content, which opens up wide possibilities for using birch bark extract in medicine, food industry and cosmetics.

In the past two decades, the biological activity of the bark extract has been demonstrated in many research centers, which have confirmed the direct regulatory activity of betulin relative to the enzymatic and enzyme systems of the body. Betulin regulates the activity of enzymes, influences the synthesis and functioning of cells. Betulin is found in many plants, but in birch bark, in comparison with other plants, the content of this substance is higher. It is betulin that protects birch wood from bacterial, fungal, viral attacks.

Betulin possess vast pharmacological properties including a wide range of anti-infective action (antiviral, antifungal, antibacterial, etc.), anti-inflammatory, antioxidant, antiradical, immunostimulating, anti-lipid and anti-atherogenic, etc. [8].

Bestim is a synthetic dipeptide - sodium salt of gamma D-glutamyl-b-tryptophan, developed at the State Research Institute of Highly Pure Biopreparations in St. Petersburg, St. Petersburg, In in vitro studies in lymphocyte culture, Bestim enhanced T-lymphocyte differentiation, and also increased the functional activity of mature mouse, rat, and human lymphocytes [9]. In this study, it is proposed to investigate the effect of betulin, beta-glucan and bestim, as well as a complex preparation composed of all three substances on some parameters of immunity.

\section{Materials and methods}

\subsection{Characteristics of test substances}

Betulin - triterpinoid, isolated from birch bark, purity of 96\%, production of LLC "Drevit", Perm.

Empirical Formula of botulin is $\mathrm{C} 30 \mathrm{H} 50 \mathrm{O} 2$, Molecular Weight: 442.72. Structural formula of botulin is presented in the figure 1 . 


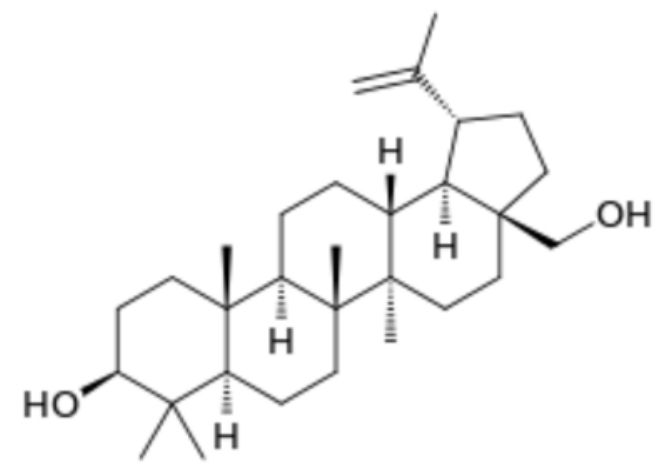

Fig. 1. Structural formula of betuline molecule.

Bestim - a synthetic dipeptide of gamma-D-glutamyl-tryptophan sodium, registration certificate 003335/03 from 01.06.2004, FGNTS NII Especially clean biopreparations of Medical-biological agency of the ministry of health of Russia, St. Petersburg.

Bestim is used in complex therapy of acute and chronic infectious and inflammatory diseases, accompanied by a decrease in cellular immunity, for prevention of infectious complications, suppression of immunity, hematopoiesis, regeneration processes in the posttraumatic and postoperative period, in the process of radiation therapy or chemotherapy, when using massive doses of antibiotics.

Structural formula of bestim molecule is presented in the figure 2 .

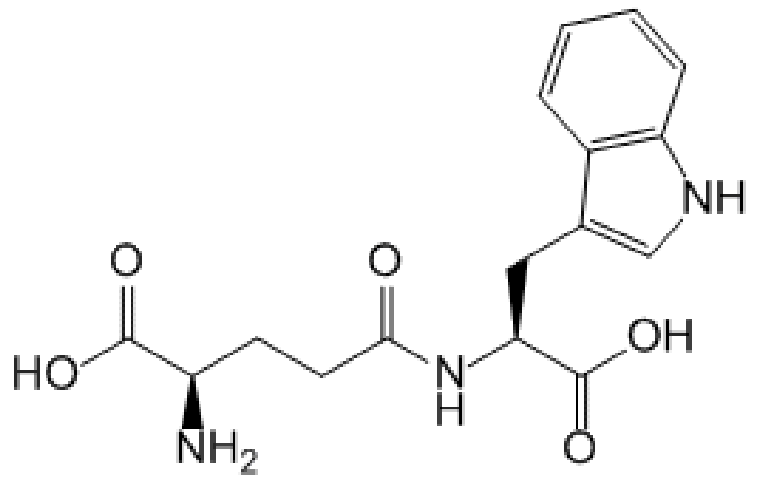

Fig. 2. Structural formula of bestim.

Bestim has a regulating effect on the reactions of cellular, humoral immunity and nonspecific resistance of the organism, stimulates the processes of regeneration in case of their oppression; improves the course of cellular metabolism. Strengthens the processes of differentiation of lymphoid cells, inducing the expression of differentiation genes on lymphocytes, normalizes the number of T-helpers, T-suppressors and their ratio in patients with various immunodeficiency states.

Beta-glucan containing preparations were obtained from the fruiting bodies of Pleurotus ostreatus mushroom, purchased at local market in St. Petersburg, Russia, dried at $60{ }^{\circ} \mathrm{C}$ and crushed into powder. To obtain beta-glucans, powderized mushroom fruit-bodies were initially boiled in $80 \%$ ethanol twice for 3 hours each time, to increase permeability of cell walls. After that water soluble beta-glucans were extracted from the residue of filtration by boiling in water 3 times for 3 hours each time and precipitated from the extract by the addition of 5 volumes of $96 \%$ ethyl alcohol at the chilling temperature $\left(4{ }^{\circ} \mathrm{C}\right)$. Precipitate 
was filtered and dried at $55{ }^{\circ} \mathrm{C}$ in air flow and crushed into powder [9]. The preparation is registered in the SGR No. 77.99.23.3.U.5270.6.09 dated 01.06.2009 under the name Fungimmun ${ }^{\circledR}$. The content of mushroom beta-glucans in the obtained dry powderized preparation was $23 \%$.

Pleurotus ostreatus is well-known and commercially important edible basidiomycetes [10]. Pleurotus ostreatus is rich in $\beta$-glucans and easily accessible as an edible mushroom. as foreign substances and hence cause a response of the immune system.

Structure of mushroom beta-glucans is presented in the figure 3.

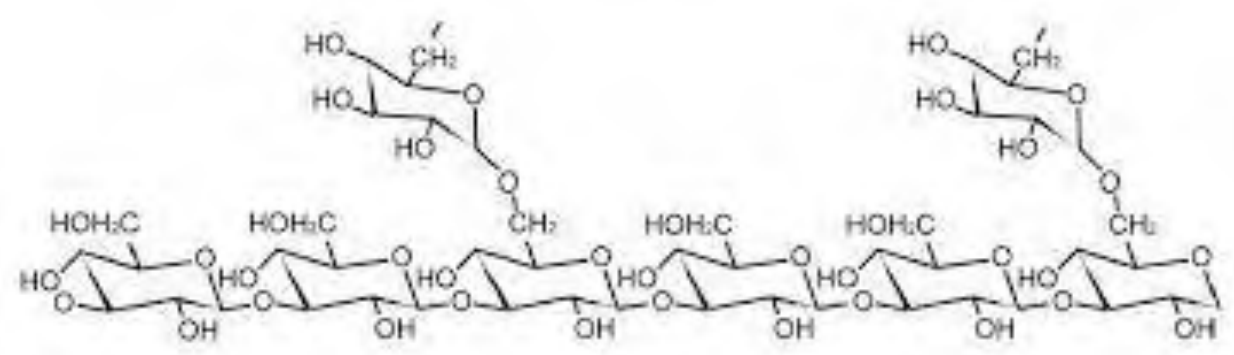

Fig. 3. Structure of mushroom beta-glucans.

The $\beta$-glucan content of the extract was estimated on dry weight basis using the $\beta$ glucan enzymatic assay kit (Megazyme International Ireland Ltd., Wicklow, Ireland) [11].

The study used white, mongrel mice, males weighing $25 \mathrm{~g}$ (Rappolovo cattery).

Diagram of preparation administration: doses of injectable preparations: betulin - $10 \mathrm{mg}$ $/ \mathrm{kg}$, mushroom betaglucan - $12.6 \mathrm{mg} / \mathrm{kg}$, bestim - $11.6 \mu \mathrm{g} / \mathrm{kg}$. The combined preparation was composed of these three substances in the above doses.

The preparations were administered to the animals intragastrically with a probe in a physiological solution in an amount of $0.5 \mathrm{ml}$. Duration of administration is 15 days with breaks for Saturday and Sunday. At the end of the experiment, the animals were weighed and then slaughtered by decapitation. From animals received spleen, thymus.

\subsection{Scope of research}

1. Counting of peripheral blood cells of mice before and after the experiment.

2. Determine the weight of animals, as well as the thymus and spleen before and after the experiment.

3. Determination of the total cellularity of the thymus and spleen (number of cells in $\mathrm{mm} 3$ ).

4. Determination of the number of antibody-forming cells in the spleen, by local hemolysis method according to Cunningham (1).

Mice and immunocompetent organs (thymus and spleen) were weighed on an AnD HR 100AZG balance. The count and characteristics of cells of peripheral blood, spleen and thymus were made on the hematological counter Abacus Junior Vet.

\subsection{Determination of the number of antibody-forming cells in the spleen of mice}

Animals 4 days before the end of the experiment were administered intravenously $0.2 \mathrm{ml}$ of a suspension of lamb erythrocytes (the concentration of cells $2 \times 107 \mathrm{in} \mathrm{mm} 3$ ) in a sterile physiological solution. To obtain splenocytes, the spleen obtained from animals was 
homogenized with scissors, the erythrocyte admixture was lysed with $0.83 \%$ ammonium chloride solution (10 min exposure). After double washing of splenocytes with physiological solution (1500 rpm, 10 minutes), a suspension of cells was prepared at a concentration of $2 \times 106$ in mm3. The spleen cells in equivalent amounts were mixed with a $10 \%$ suspension of lamb erythrocytes. In an amount of 200 .mu.l, the resulting mixture of cells was placed in a space between two slides joined by a double-sided adhesive tape, incubated for 1 hour at $37^{\circ} \mathrm{C}$. At the end of the incubation, the number of lysis zones was counted over the entire area of the glass. The results were expressed as the number of antibody-forming cells in $\mathrm{mm} 3$.

The reliability of differences in the average indicators was determined on the basis of a single-factor analysis of variance with fixed effects.

\section{Results and discussion}

At the conclusion of the experiment, we did not detect changes in the weight of mice, as well as any quantitative or qualitative changes in the composition of their peripheral blood, compared with the control (in this connection, data are not given).

At the same time, at the end of the experiment, we observed a significant increase in the thymus weight $(p<0.05)$ in groups of animals that were injected intragastrically with a probe: bestim, fungal beta-glucan, and a combined preparation. However, when using the parameter such as the "mass coefficient of the thymus", which is the ratio of the weight of the thymus to the weight of the animal, in the evaluation of these changes, significant changes were noted only in the groups receiving bestim and beta-glucan. Cellularity of the thymus increased only in mice that received the combined preparation. We have not identified the reaction of the thymus to the administration of betulin.

Initially mice were weighted and divided into groups with equal weight. Results are presented in the table 1.

A study of the dynamics of the weight of the spleen in response to feeding with the preparations studied showed that a significant increase $(p<0.05)$ of organ weight and the "mass coefficient of the spleen" was observed only in the group of animals treated with the combined preparation (Table 2). At the same time, we noted a decrease in these parameters in mice fed with betulin and fungal beta-glucan.

Table 1. Weights of the mice before and after administration of tested preparations.

\begin{tabular}{|c|c|c|}
\hline \multirow{2}{*}{ Group } & \multicolumn{2}{|c|}{ Average weight of the mouse in a group } \\
\cline { 2 - 3 } & $\begin{array}{c}\text { Before administration } \\
\text { of the preparation }\end{array}$ & $\begin{array}{c}\text { After administration of the } \\
\text { preparation }\end{array}$ \\
\hline Control & $22,8 \pm 2,4$ & $23,6 \pm 4,2$ \\
\hline Betulin & $23,2 \pm 2,8$ & $25,3 \pm 5,4$ \\
\hline Beta-glucan & $24,5 \pm 2,3$ & $24,8 \pm 1,4$ \\
\hline Bestim & $23,7 \pm 0,7$ & $24,7 \pm 0,3$ \\
\hline Complex & $24,2 \pm 1,8$ & $24,5 \pm 1,1$ \\
\hline
\end{tabular}


No significant difference in theincrease of the weight of a the animals in different groups was detected.

Table 2. Influence of the studied preparations on the weight characteristics and cellularity of the thymus and spleen of mice.

\begin{tabular}{|c|c|c|c|c|c|c|}
\hline Indicators & $\begin{array}{l}\text { Animal groups } \\
\text { (number of } \\
\text { animals in a } \\
\text { group) }\end{array}$ & $\begin{array}{c}\text { Average } \\
\text { Values, M }\end{array}$ & $\begin{array}{c}\text { Dispersion, } \\
\text { D }\end{array}$ & $\begin{array}{c}\text { Criterion, } \\
\text { F }\end{array}$ & $\begin{array}{c}\text { Critical } \\
\text { value F for } \\
\alpha=0,05\end{array}$ & $\begin{array}{c}\text { Significance } \\
\text { level, } \mathrm{P}\end{array}$ \\
\hline \multirow{5}{*}{$\begin{array}{c}\text { Spleen } \\
\text { weight, g }\end{array}$} & Control (10) & $\underline{0,27}$ & 0,002 & & & \\
\hline & Betulin (8) & $\underline{0,20}$ & 0,004 & 8,7 & 4,49 & $\underline{0,009}$ \\
\hline & Beta-glucan (8) & $\underline{0,21}$ & 0,008 & 12,17 & 4,6 & $\underline{0,004}$ \\
\hline & Bestim (8) & 0,29 & 0,009 & 0,21 & 4,6 & 0,65 \\
\hline & Complex (10) & 0,35 & 0,001 & 10,8 & 4,6 & $\underline{0,005}$ \\
\hline \multirow{5}{*}{$\begin{array}{l}\text { Thymus } \\
\text { weight, g }\end{array}$} & Control (10) & 0,09 & 0,0002 & & & \\
\hline & Betulin (8) & 0,09 & 0,0003 & 0,09 & 4,49 & 0,1 \\
\hline & Beta-glucan (8) & $\underline{0,12}$ & 0,0001 & 24,2 & 4,6 & $\underline{0,0002}$ \\
\hline & Bestim (8) & $\underline{0,13}$ & 0,0001 & 26,0 & 4,6 & $\underline{0,0002}$ \\
\hline & Complex (10) & $\underline{0,11}$ & 0,0002 & 5,54 & 4,6 & $\underline{0,03}$ \\
\hline \multirow{3}{*}{$\begin{array}{l}\text { Thymus } \\
\text { cellularity } \\
\text { (count in } \\
\mathrm{mm}^{3} \text { ) }\end{array}$} & Control (10) & 79,77 & 752,34 & & & \\
\hline & Betulin (8) & 53,27 & 820,15 & 3,98 & 4,49 & 0,06 \\
\hline & Complex (10) & $\underline{117,87}$ & 1226,91 & 5,9 & 4,6 & $\underline{0,03}$ \\
\hline \multirow{5}{*}{$\begin{array}{c}\text { Mass } \\
\text { coefficient of } \\
\text { spleen }\end{array}$} & Control (10) & $\underline{11,71}$ & 2,21 & & & \\
\hline & Betulin (8) & $\underline{8,19}$ & 9,89 & 9,93 & 4,49 & $\underline{0,006}$ \\
\hline & Beta-glucan (8) & $\underline{8,28}$ & 1,76 & 21,53 & 4,6 & $\underline{0,0004}$ \\
\hline & Bestim (8) & 11,91 & 16,79 & 0,017 & 4,6 & 0,89 \\
\hline & Complex (10) & $\underline{14,39}$ & 3,9 & 9,51 & 4,8 & $\underline{0,008}$ \\
\hline \multirow{5}{*}{$\begin{array}{c}\text { Mass } \\
\text { coefficient of } \\
\text { thymus }\end{array}$} & Control (10) & 3,88 & 0,22 & & & \\
\hline & Betulin (8) & 3,81 & 0,96 & 0,03 & 4,49 & 0,85 \\
\hline & Beta-glucan (8) & $\underline{5,17}$ & 0,24 & 26,4 & 4,6 & $\underline{0,0001}$ \\
\hline & Bestim (8) & $\underline{5,20}$ & 0,24 & 28,09 & 4,6 & $\underline{0,0001}$ \\
\hline & Complex (10) & 4,54 & 0,71 & 4,14 & 4,6 & 0,06 \\
\hline
\end{tabular}

All studied preparations, except for betulin, significantly $(p<0.05)$ increased the number of antibody-forming cells in the spleen (Table 3.) 
Table 3. The levels of antiboby forming cells (AFC, Ln) in mice spleen at oral administration of the preparations.

\begin{tabular}{|c|c|c|c|c|c|}
\hline $\begin{array}{c}\text { Animal } \\
\text { groups }\end{array}$ & $\begin{array}{c}\text { Amount of } \\
\text { AFC, Ln }\end{array}$ & $\begin{array}{c}\text { Dispersion, } \\
\mathrm{D}\end{array}$ & $\begin{array}{c}\text { Criterion, } \\
\mathrm{F}\end{array}$ & $\begin{array}{c}\text { Critical } \\
\text { value F for } \\
\alpha=0,05\end{array}$ & $\begin{array}{c}\text { Significance level, } \\
\mathrm{P}\end{array}$ \\
\hline Control & 4,31 & 0,08 & & & 0,26 \\
\hline Betulin & 4,09 & 0,32 & 1,38 & 5,11 & $\underline{0,01}$ \\
\hline Beta-glucan & $\underline{4,98}$ & 0,17 & 9,64 & 5,11 & $\underline{0,0002}$ \\
\hline Bestim & $\underline{5,08}$ & 0,04 & 28,05 & 4,84 & $\underline{0,0002}$ \\
\hline Complex & $\underline{5,28}$ & 0,12 & 28,20 & 4,84 & \\
\hline
\end{tabular}

Note: The underlined averages of the AOK number, Ln and significance levels (P) have a statistically significant difference $(\mathrm{P}<0.05)$ with respect to the control group of the animals.

\section{Conclusion}

The results of the study showed that bestim, beta-glucan, as well as a combined preparation consisting of bestim, betulin and beta-glucan under the conditions of our experiment (15 days of feeding with interruptions and administration of the preparation in a single dose) have an immunotropic effect, which is confirmed by reliable increase in the mass of the thymus, as well as the "mass ratio of the thymus".

The reaction of the spleen of animals to the studied preparations was less obvious. Significant changes were detected only in the group of mice, whose diet included a combined preparation.

We also found that the administration of bestim, beta-glucan and the combination preparation significantly increase the number of antibody-forming cells in the spleen, which indicates the stimulation of humoral immunity of animals by these preparations.

Thus, the combined preparation showed a tendency to a more pronounced effect on the immune system. However, the immunotropic effect of the A complex preparation appears to be due to bestim and beta-glucan as under the conditions of our experiment, we observed an insignificant but reliable decrease in the studied parameters in mice receiving betulin. Most likely, in contrast to beta-glucan and bestim, which exercise their immunomodulatory effect through binding to receptors localized on the cells of the immune system, the regulation of cellular activity by betulin is realized due to the membranotropic properties of triterpene glycosides. As a result of the interaction of cell membranes with triterpenes, depending on the dose, either ion channels or pores are formed, which change the state of the lipid bilayer and the biological activity and viability of cells. According to the literature, the influence of this class of bioregulators on the immune system is rather limited and is mainly associated with interferonogenic action and influence on phagocytosis. However, when creating a combined preparation of immunomodulatory action, the inclusion in the composition of a substance with antiviral and interferonogenic action may be very promising. 


\section{References}

1. M.T. Islam, Ch. Sarkar, D.M. El-Kersh, S. Jamaddar, Sh.J. Uddin, J.A. Shilpi, M.S. Mubarak, Natural products and their derivatives against coronavirus: A review of the non-clinical and pre-clinical data, Phytotherapy Research 34, 10, 2471-2492 (2020)

2. A.J. Cunningham, $A$ method of increased sensitivity for detecting single antibodyforming cells, Nature 207, 5001, 1106-1107 (1965)

3. M. Shamtsyan, Potential to develop functional food products from mushroom bioactive compounds, Journal of Hygienic Engineering and Design 15, 51-59 (2016)

4. Z. Béni, M. Dékány, B. Kovács, et al., Bioactivity-Guided Isolation of Antimicrobial and Antioxidant Metabolites from the Mushroom Tapinella atrotomentosa, Molecules 23(5), 1082 (2018) Published 2018 May 4. doi:10.3390/molecules23051082

5. S.S. Kumar, N. Gautam, Chemical and Bioactive Profiling, and Biological Activities of Coral Fungi from Northwestern Himalayas, Sci. Rep. 7, 46570 (2017) https://doi.org/10.1038/srep46570

6. M.M. Anisimov, G.N. Likhatskaya, E.B. Shentsova, N.G. Prokof'eva, L.S. Shevchenko, E.A. Nurminski, E.V. Trifonov, N.F. Samoshina, M.V. Denisenko, N.I. Uvarova, Biological activities and mechanisms of action of betulin glycosides, Intern. conf. on saponins "Phytochemistry and Application of Plant Saponins", Pulawy, Poland, 8-10 Sept. 2004: Book abstrs. Pulawy (2004)

7. C.M. Soica, C.A. Dehelean, C. Peev, M. Aluas, I. Zupkó, P.Jr. Kása, E. Alexa, Physico-chemical comparison of betulinic acid, betulin and birch bark extract and in vitro investigation of their cytotoxic effects towards skin epidermoid carcinoma (A431), breast carcinoma (MCF7) and cervix adenocarcinoma (HeLa) cell lines, Nat. Prod. Res. 26(10), 968-74 (2012) doi: 10.1080/14786419.2010.545352.

8. N.H. Harun, A.W. Septama, W.A.N.W. Ahmad, R. Suppian, Immunomodulatory effects and structure-activity relationship of botanical pentacyclic triterpenes: $A$ review, Chinese Herbal Medicines 12, 2, 118-124 (2020)

9. M. Shamtsyan, E. Antontceva, A. Panchenko, N. Petrishchev, Hyperlipidemic and hypocholesterolic action of submerge cultured mushrooms, Journal of Hygienic Engineering and Design 7, 96-99 (2014)

10. E. Antontceva, S. Sorokin, M. Shamtsyan, L. Krasnikova, (2018). Influence of Pleurotus ostreatus preparations on fermentation products of lactic acid cultures, Journal of Hygienic Engineering and Design 22, 47-52 (2018)

11. Mushroom and yeast beta-glucan assay procedure (K-YBGL 12/16), Megazyme International Ireland (2016) https://secure.megazyme.com/files/Booklet/KYBGL_DATA.pdf 